\title{
Sexuality of Repartnered Men and Women in France: Sexual Behaviors, Perceptions, Expectations and Sexual Dysfunctions
}

\author{
Marie-Helene Colson ${ }^{1 *}$, Antoine Lemaire ${ }^{2}$, Patrick Klein ${ }^{3}$ \\ ${ }^{1}$ CRIR-AVS, Sce Pr Lançon, Hôpital Ste Marguerite, Marseille, France \\ ${ }^{2}$ ADIRS, Lille, France \\ ${ }^{3}$ IPSOS Health Institute, Paris, France \\ Email: " ${ }^{*}$ marie.helene@colson.fr, ${ }^{*}$ marie-helene.colson@univmed.fr
}

Received October 30, 2011; revised November 31, 2011; accepted December 12, 2011

\begin{abstract}
Introduction: Although many epidemiological studies on sexuality have been published, none have specifically addressed male and female sexuality in repartnered couples. Aim: To investigate men and women's sexual behaviors, perceptions and expectations, and the frequency of their sexual dysfunctions, with a focus on repartnered couples, i.e, subjects living with a partner in a stable relationship after divorce or widowhood (including both remarried couples and cohabitating unmarried couples). Methods: Analysis of telephone survey data collected from 1002 French subjects (483 men, 519 women) $\geq 35$ years. Of these, 748 were living with their partner as part of a heterosexual couple. For these subjects, the sexuality of 149 repartnered subjects was compared to that of the other 599 subjects. Main Outcome: Measures: A 39-item questionnaire assessing subjects' perceptions, expectations, sexual behaviors and dysfunctions. Results: Compared with other subjects, men and women in repartnered couples had more active sexuality and more interest in sexuality (men $93 \%$ vs $80 \%, P<0.01$, women $73 \%$ vs $65 \%, P<0.05$ ). They were generally more sensitive to feelings and emotions linked to their sexuality, and these feelings seemed to increase steadily with age. Their sexuality was more attuned to their partner's pleasure (men $79 \%$ vs $59 \% P<0.001$, women $50 \%$ vs $34 \%, P<0.01$ ). Concern for the future of the relationship and for sexuality was equally present for both groups, although repartnered couples were more often concerned about potential inadequacy and conflicts between the two partners. Although repartnered men seemed to be less affected by diminished desire, they had slightly higher rates of premature ejaculation and erectile dysfunction, and considered their quality of life to be more affected by these problems. Conclusion: The sexuality of repartnered couples remains poorly studied, but seems to differ from that of non-repartnered couples. Our findings open interesting avenues of research on the diagnosis and management of repartnered couples.
\end{abstract}

Keywords: Repartnered Couples; Remarried Couples; Sexual Behavior; Sexual Inadequency; Marital Relationship

\section{Introduction}

A significant percentage of men and women form new relationships after divorce or widowhood, and these repartnered couples represent one of the clearest examples of the evolution of contemporary couples and families (Dejong, 2004) [1]. Therapists must therefore deal with this new reality. In France today, $41 \%$ of all marriages end in divorce. In 1994, out of a total of 7.7 million couples, there were 660,000 families headed by remarried couples (Desplanques, 1990) [2], and by the last French census in 1999, this number had risen to over 700,000 (Barre, 2004) [3]. There is currently little known about repartnered couples without children, for whom data are extremely scarce. In Canada in 2001, the probability of forming a

${ }^{*}$ Corresponding author. new relationship after a divorce was $30 \%$ for $30-49$ year-old individuals (Statistiques Canada, 2002) [4]. In the United States, where $46 \%$ of marriages are remarriages, the repartnered couple - with or without children will be the general rule (Vischer et al 2003) [5]. The objective of this survey is to highlight original data on the sexuality of repartnered couples, about whom little research has been published.

\section{Material and Methods}

We administered a semi-qualitative sex survey to 1002 French men and women aged 35 years or older, representative of the French population. Of these, 748 were living with their partner as part of a heterosexual couple. For these 748 subjects, the sexuality of 149 repartnered 
subjects was compared to that of the other 599 subjects. The study was performed in accordance with the general principles of qualitative health research (Ullin et al, 2002) [6], such as defined in the framework of international consensus conferences (Hirsh et al, 2004) [7] and more generally in evidence-based medicine (Mc Govern et al, 2003) [8]. Since this was a telephone interview survey, no ERB submission was required for this study according to French regulations.

This study also provides an update of the last analysis of sexual practices among men and women in France, performed in 1992 (ACSF study1992) [9] and 2008 (Bajos et al, 2008) [10].

\subsection{Population}

The survey was conducted in France on a sample of 1002 subjects (483 men and 519 women) aged 35 years or older, from November 4 to 15, 2003. Telephone interviews were conducted by professionals using the CATI system (computer-assisted telephone interview) and dedicated questionnaires. The representativeness of the French population was assured by randomization according to the quota method, with the following parameters obtained from the last INSEE (Institut National de la Statistique et des Études Économiques (National Institute of Statistics and Economic Studies)), census conducted in 1999: gender, age, occupation of the head of the family, and location of residence (town/city and administrative department). The global sample was stratified according to five French geographic areas (north, south, east, west and central), and includes about 200 subjects per region.

The questionnaire itself was conducted in two steps. A pilot study was first conducted on a small sample of subjects. This first version of the questionnaire was then discussed and revised by a group of experts.

For the purposes of the study, we defined repartnered subjects as men and women living with a partner in a new, stable, heterosexual relationship after divorce, widowhood, or end of a previous cohabitating relationship. Repartnered couples include both remarried couples and cohabitating unmarried couples. Non-repartnered subjects are those subjects living with a partner in a stable relationship for the first time. Non-repartnered couples include both married couples and cohabitating unmarried couples.

The population of repartnered men and women was great enough to allow us to investigate potential differences between their sexual experiences, behaviors and expectations and those of non-repartnered men and women.

\subsection{Survey and Study Outcomes}

An English translation of the complete questionnaire is available in the appendix (see Appendix 1). Study outcomes were sexual behavior, mental perceptions of sexuality, level of satisfaction, expectations concerning sex life, and sexual complaints and dysfunctions. Other data have been more thoroughly addressed in other publications (Colson et al, 2006) [11], (Colson et al, 2007) [12] (Lemaire et al, 2009) [13] or will be treated in future work.

\subsection{Statistical Analysis}

The questionnaires were entered on the CATI system using the software QUANCEPT, (Software, version 7.9, SPSS Inc., Chicago) enabling direct entry of responses on a computer enabling automatic scrolling display of the questionnaire (including filters, cues, etc.), random display of questions or sets of questions, random display of modes of reply, and real-time follow-up of the sample. The results were adjusted at the regional level according to the data generated from the last INSEE census (1999), and weighted as a function of the true impact of the region nationally, assuring the representativeness of the whole.

We conducted analyses of variance (ANOVA), with the level of significance set at $P<0.05$. There was no significant difference between the distribution of the two groups repartnered subject, male or female, and the other group, on any variable.

\section{Results}

\subsection{Study Population}

The main characteristics of the 1002 subjects are given in Table 1. Overall, $74.7 \%$ of subjects (748) 35 years old or older reported that they were living with a partner. Of these, $14.9 \%$ (149) were part of a repartnered couple. Among the 483 men, 308 formed non-repartnered couples, 73 formed repartnered couples and 102 were not living as a couple. Among the 519 women questioned, 290 formed non-repartnered couples, 77 formed repartnered couples and 152 were not living with a partner. For subjects living alone, $12.3 \%$ were widowed, $5.3 \%$ separated or divorced, and $12.3 \%$ single. The analysis conducted here compares the sexuality of repartnered subjects to that of the other individuals.

\subsection{Greater Sexual Vitality in Repartnered Couples}

\subsubsection{More Frequent Sexual Intercourse for Individuals Living in Repartnered Couples, Particularly Older Ones}

Men and women living in repartnered couples seemed to be slightly more sexually active (sexual intercourse 2.3 vs 1.8 times/week for non-repartnered couples $(P<0.05)$, 
and 1.6 for unmarried, widowed or divorced). Although $16 \%$ of the total sample had no sexual activity, that was the case for only $8 \%$ of those forming repartnered couples (Table 2). This difference was even more pronounced for the older subjects. Among repartnered couples, $70 \%$ of the 55 - 59 year olds, $77 \%$ of the 60 - 64 year olds and $50 \%$ of those $\geq 70$ years old reported having sexual intercourse $>2$ times a week, while this was the rate for only $50 \%, 34 \%, 35 \%$ and $31 \%$ of the other subjects of the same ages, respectively.

Table 1. Demographic and social characteristics of the 1002 individuals comprising the study population.

\begin{tabular}{|c|c|}
\hline Parameter & $\mathrm{N}(\%)$ \\
\hline Total & $1002(100)$ \\
\hline \multicolumn{2}{|l|}{ Gender } \\
\hline Male & $483(48.2)$ \\
\hline Female & $519(51.8)$ \\
\hline \multicolumn{2}{|l|}{ Age group (years) } \\
\hline$[35-44]$ & $317(31.6)$ \\
\hline$[45-59]$ & $395(39.4)$ \\
\hline$[60-69]$ & $201(20.1)$ \\
\hline$>70$ & $89(8.9)$ \\
\hline \multicolumn{2}{|l|}{ Relationship status } \\
\hline Lives in couple & $748(74.7)$ \\
\hline Non-repartnered couple & $599(59.8)$ \\
\hline repartnered couple & 149 (14.9) \\
\hline Does not live in couple & $254(25.3)$ \\
\hline Single & 123 \\
\hline Divorced/Separated & $53(5.3)$ \\
\hline Widowed & $123(12.3)$ \\
\hline \multicolumn{2}{|l|}{ Education } \\
\hline Less than high school & $564(56.3)$ \\
\hline High school graduate & $163(16.3)$ \\
\hline College graduate & $271(27.0)$ \\
\hline \multicolumn{2}{|l|}{ Monthly income $(€)$} \\
\hline$<1143$ & $200(20.0)$ \\
\hline [1143-1982] & $306(30.5)$ \\
\hline [1982-3048] & $248(24.8)$ \\
\hline$>3048$ & $158(15.8)$ \\
\hline \multicolumn{2}{|l|}{ Employment status } \\
\hline Farmer & $16(1.6)$ \\
\hline Self-employed & \\
\hline (craft sector/shopkeepers)/ & $27(2.7)$ \\
\hline \multicolumn{2}{|l|}{ Head of one's enterprise } \\
\hline Senior professional & $102(10.2)$ \\
\hline White-collar worker & $152(15.2)$ \\
\hline Employee & $167(16.7)$ \\
\hline Blue-collar worker & $144(14.4)$ \\
\hline Pensioner & $292(29.1)$ \\
\hline Unemployed & $102(10.2)$ \\
\hline \multicolumn{2}{|l|}{ Residence } \\
\hline Rural & $262(26.1)$ \\
\hline$<20,000$ residents & $174(17.4)$ \\
\hline$[20,000-100,000]$ residents & $133(13.3)$ \\
\hline$>100,000$ residents & $274(27.3)$ \\
\hline Paris and suburbs & $158(15.8)$ \\
\hline
\end{tabular}

(No significant difference between repartnered subjects and other).
Table 2. Weekly mean of rate of sexual intercourse subjects living or no in a repartnered couple.

\begin{tabular}{cccc}
\hline & $\begin{array}{c}\text { Repartnered } \\
\text { Couples }\end{array}$ & $\begin{array}{c}\text { Non Repartnered } \\
\text { Couples }\end{array}$ & $P$ value \\
\hline$>4$ /week (\%) & 19 & 11 & $P<0.05$ \\
$3-4$ week (\%) & 19 & 17 & $\mathrm{NS}^{*}$ \\
$2-3 /$ week $(\%)$ & 29 & 25 & $\mathrm{NS}^{*}$ \\
Total $>$ 2/week (\%) & 67 & 53 & $P<0.01$ \\
$1-2 /$ week $(\%)$ & 15 & 17 & $\mathrm{NS}^{*}$ \\
$<1 /$ week $(\%)$ & 10 & 14 & $\mathrm{NS}^{*}$ \\
Never $(\%)$ & 8 & 16 & $P<0.01$ \\
\hline
\end{tabular}

${ }^{*}$ No Significance.

\subsubsection{More Interest in Sexuality}

For most of the participants in the study $(80 \%$ of men and $65 \%$ of women), sexuality was considered to be an important part of life. However, it seemed to be even more important for individuals in repartnered couples (93\% of men and $73 \%$ of women $P<0.001)$.

In studies of this kind, more men than women respond that they are interested in sex (Colson et al, 2006 [11]) (Laumann et al, 2005) [14], Our inquiry confirmed that generality: twice as many men responded yes to question $2-2$, "Do you feel that you think about sexuality frequently?" (61\% vs $31 \%$ for women, $P<0.001)$. However, men and women forming repartnered couples answered yes to that question significantly more frequently $(78 \%$ and $41 \%$, respectively, $P<0.001)$.

Lack of sexual intercourse for several months was viewed indifferently by $17 \%$ of the men and $34 \%$ of the women overall, but for repartnered couples, those values were $7 \%$ and $29 \%, P<0.0001$, respectively.

\subsubsection{Sexuality Seems to Remain Important Longer in Repartnered Couples}

The importance of sexuality diminished progressively with age in the lives of all the subjects interviewed, including members of repartnered couples. But for these repartnered men and women, it remained a more important factor: $93 \%$ of 35 - 44 year olds, $86 \%$ of 45 - 59 year olds, $61 \%$ of 60 - 69 year olds and $68 \%$ of those $\geq 70$ years old, as opposed to $89 \%, 77 \%, 52 \%$ and $34 \%$ of the rest of the population of the same ages, respectively.

\subsubsection{Sexual Satisfaction}

Sexual satisfaction was evaluated on a scale from 0 to 10 . There was no difference between repartnered and nonrepartnered subjects: $40 \%$ of the individuals in each group rated sexual satisfaction $\geq 8 / 10$.

\subsection{More Romantic Sexuality in Repartnered Couples?}

\subsubsection{Repartnered Men and Women Pay More Attention to Their Partner's Pleasure}

Both repartnered and non-repartnered women tended to 
be receptive rather than active in their sexual behavior. As a general rule, relatively few women reported regularly trying to give pleasure to their partner (38\% of members of repartnered couples and $34 \%$ of members of non-repartnered couples). Differences were greater for men, with a high percentage of male members of repartnered couples reporting that they tried to give their partner pleasure (79\% vs 59\% for other men $P<0.001)$, and that they sought to achieve simultaneous orgasms $(50 \%$ vs $34 \%$ for other men $P<0.01$ ).

\subsubsection{The Importance of Feelings and Love Increases with Age for Repartnered Couples}

The reported importance of feelings for partners in repartnered couples generally increased with age: $34 \%$ of 35 - 44 year olds, $41 \%$ of 45 - 59 year olds, $51 \%$ of 60 69 year olds, and $35 \%$ of those 70 years and older, while it seemed to stabilize or decline with age for the other subjects interviewed $(43 \%, 35 \%, 32 \%$ and $7 \%$ for the four age groups) (Table 3 ).

\subsubsection{Initiating Sexual Intercourse}

With respect to initiating sexual intercourse, a subject's status as a member of a repartnered or non-repartnered couple was less important than whether the subject was a man or a woman. More repartnered than non-repartnered subjects reported that sharing a good time together was the best way to initiate sexual intercourse $(61 \%$ vs $46 \%$, $P<0.001 \%$ ). Eating a good meal together was reported to be a good "trigger" for sexual activity in repartnered French couples, for men ( $21 \%$ vs $6 \%$ for non-repartnered, $P<0.001 \%)$ and women (15\% vs $9 \%, P<0.01)$.

\subsection{Communication between Partners}

\subsubsection{A Greater Capacity for Dialogue and Communication in Repartnered Couples}

According to our data, $61 \%$ of members repartnered couples claimed it was "very easy" to talk with their partners, compared with $46 \%$ of the other subjects $(P<0.01 \%)$. Differences were more marked across age groups: for 45 59 year olds, $69 \%$ of members of repartnered couples vs. $48 \%$ of others, and for 60 - 69 year olds, $54 \%$ vs $39 \%$ ( $P$ $<0.01 \%$ ).

Table 3. What is the more important for you when you make love? Answer: emotions and feelings.

\begin{tabular}{cccc}
\hline & $\begin{array}{c}\text { Men and Women } \\
\text { living in repartnered } \\
\text { couple (\%) }\end{array}$ & $\begin{array}{c}\text { Men and Women living } \\
\text { in non repartnered } \\
\text { couple }(\%)\end{array}$ & Significance \\
\hline $35-44 \mathrm{y}$ & 34 & 43 & $\mathrm{NS}^{*}$ \\
$44-59 \mathrm{y}$ & 41 & 35 & $P<0.05$ \\
$60-69 \mathrm{y}$ & 51 & 32 & $P<0.001$ \\
$>70 \mathrm{y}$ & 35 & 7 & $P<0.0001$ \\
\hline
\end{tabular}

*No significant.

\subsubsection{Talking about Sexual Behavior}

Overall, this topic was easier for men to broach than for women $(21 \%$ vs $11 \%, P<0.001)$. This held true for men, regardless of their relationship status. Women were generally uncomfortable talking about their sex lives (89\%), but women who were part of a repartnered couple reported speaking slightly more freely (20\% vs $11 \%$ for other women $P<0.001$ ).

\subsubsection{Talking about Love and Romantic Feelings}

Men and women today generally feel free to express their romantic feelings and to talk about these feelings with their partners. Members of repartnered couples did so slightly more freely $(82 \%)$ than non-repartnered couples $(70 \%)$. This difference in talking openly about romantic feelings was even clearer for older members of repartnered couples ( $87 \%$ vs $70 \%$ for 45 - 59 year olds, $91 \%$ vs $69 \%$ for 60 - 69 year olds, and $84 \%$ vs $55 \%$ of those 70 years or older).

\subsection{Worries and Expectations}

The lives of repartnered couples were not however free of worries and expectations.

\subsubsection{Concerns about the Future of the Couple's Sexuality}

These worries were mainly about the fear of aging and were less common for repartnered couples than for others (36\% for repartnered men vs $51 \%$ the other men, $P<$ $0.005)$. Women were as sensitive to these concerns as men, but women living alone were less concerned (34\%) than those who were members of repartnered couples $(50 \%)$ or non-repartnered couples $(51 \%)$. Repartnered men reported concern about sexual dysfunction $(23 \%$ vs $13 \%$ of non-repartnered men) and about the future harmony of their relationship (23\% vs $17 \%$ of non-repartnered men). The rates for women were $20 \%$ vs $17 \%$.

\subsubsection{Hopes for the Couple's Future Sexuality}

In general, the men and women interviewed did not want their current sexuality to change in any way. Some men wanted more active sex lives, especially repartnered men ( $23 \%$ vs $17 \%$ for other men). It should be noted, however, that only $2 \%$ of repartnered women wanted better quality sexual intercourse, versus $10 \%$ of other women $(P<0.01)$.

\subsubsection{Fidelity}

This topic was not broached directly. But $33 \%$ of the men and $4 \%$ of the women interviewed acknowledged a desire for a partner other than their spouse or partner. These rates were $48 \%$ for repartnered men vs. only $28 \%$ of non-repartnered men $(P<0.01)$, with rates of $2 \%$ vs $3 \%$ for women (NS). 


\subsubsection{Performance}

Our data confirmed that sexual performance was generally more important for men than for women. In response to question 14 "When you make love, do you try to perform well?", $41 \%$ of men vs. $26 \%$ of women ( $P<$ 0.01 ) answered "always" or "often". This rate was somewhat higher for repartnered men than for non-repartnered men $(49 \%$ vs $37 \%, P<0.05)$. Women seem to be less driven by performance, both for repartnered $(25 \%)$ and non-repartnered women (28\%) (NS).

\subsection{Sexual Dysfunction in Repartnered Couples}

\subsubsection{Frequency and Distribution}

Although repartnered men seemed to be slightly less affected by sexual desire disorders than other men (lack of sexual desire $18 \%$ vs $24 \%$ ), they reported experiencing premature ejaculation more frequently ( $32 \%$ vs $23 \%$ for other men). For women, lack of desire was quite common and affected repartnered women and non-repartnered women equally ( $47 \%$ for both groups, NS). Repartnered women reported slightly more frequent sexual difficulties than did other women (anorgasmy: 19\% vs $13 \%$; dyspareunia: $16 \%$ vs $15 \%$; vaginismus: $7 \%$ vs $5 \%$, respectively). (Table 4).

\subsubsection{More Frequent Erectile Dysfunctions in Repartnered Couples?}

Mild erectile dysfunction was more frequently reported by single men than other men $(50 \%$ vs $40 \%$ for members

Table 4. Female and male sexual difficulties, and the importance of relationship status.

\begin{tabular}{|c|c|c|c|c|c|}
\hline $\begin{array}{c}\text { Sexual } \\
\text { difficulties }\end{array}$ & $\begin{array}{l}\text { All } \\
(\%)\end{array}$ & $\begin{array}{l}\text { All } \\
\text { couples } \\
(\%)\end{array}$ & $\begin{array}{l}\text { Repartnered } \\
\text { couples } \\
(\%)\end{array}$ & $\begin{array}{l}\text { Non-Repartnered } \\
\text { couples } \\
(\%)\end{array}$ & $\begin{array}{c}\text { Single or } \\
\text { not } \\
\text { married } \\
(\%)\end{array}$ \\
\hline \multicolumn{6}{|l|}{ Female } \\
\hline Dyspareunia & 16 & 15 & $16^{*}$ & $15^{*}$ & $20^{* *}$ \\
\hline Lack of desire & 46 & 47 & $47^{*}$ & $47^{*}$ & $46^{*}$ \\
\hline Anorgasmy & 16 & 14 & $19^{* *}$ & $13^{* *}$ & $26^{* *}$ \\
\hline Vaginismus & 6 & 6 & $7^{*}$ & $5^{*}$ & $9^{*}$ \\
\hline \multicolumn{6}{|l|}{ Male } \\
\hline $\begin{array}{l}\text { Mild erectile } \\
\text { dysfunctions }\end{array}$ & 42 & 40 & $43^{* *}$ & $39^{* *}$ & $50^{* *}$ \\
\hline $\begin{array}{l}\text { Severe Erectile } \\
\text { dysfunctions }\end{array}$ & 20 & 17 & $23^{* *}$ & $16^{* *}$ & $29^{* *}$ \\
\hline $\begin{array}{l}\text { Premature } \\
\text { ejaculation }\end{array}$ & 24 & 25 & $32^{* *}$ & $23^{* *}$ & $23^{* *}$ \\
\hline $\begin{array}{l}\text { Delayed } \\
\text { ejaculation }\end{array}$ & 9 & 6 & $5^{*}$ & $7^{*}$ & $19^{* * *}$ \\
\hline Lack of desire & 25 & 23 & $18^{* * *}$ & $24^{* * *}$ & $39^{* * *}$ \\
\hline
\end{tabular}

of couples). Single men also reported more severe and worrisome erectile difficulties ( $29 \%$ vs $23 \%$ for repartnered men and 16\% for non-repartnered men, Table 4). Similar values were found for women, who were asked if they had ever encountered severe erectile difficulties in their partner: $34 \%$ of single women, $31 \%$ of repartnered women, but only $18 \%$ of non-repartnered women $(P<$ $0.01)$.

\subsubsection{Repartnered Men and Women Experience More Distress Due to Erectile Dysfunction}

In our study, sexual dysfunction affected quality of life more often for repartnered men ( $46 \%$ vs $31 \%$ of other men). Worries and anxiety about sexual dysfunction increased with age, for both men and women, affecting $29 \%$ of repartnered subjects vs $28 \%$ of non-repartnered subjects in the 35 - 44 year old group, $62 \%$ vs $32 \%$ in the 45 - 59 year old group $(P<0.001)$, and $57 \%$ vs $34 \%$ in the 60 - 69 year old group $(P<0.01)$.

In our study, erectile dysfunction seemed to be more poorly tolerated by repartnered men than by non-repartnered men (Table 5). Repartnered men were more likely to report an impact on their confidence $(42 \%$ vs $24 \%$ of other men, $P<0.001)$, their $\operatorname{mood}(50 \%$ vs $34 \%$ ), their feelings for their partner ( $29 \%$ vs $20 \%)$, the harmony of their relationship ( $44 \%$ vs $27 \%)$, their psychological well-being ( $46 \%$ vs $28 \%$ ), and their own sexual desires ( $49 \%$ vs 30\%). For repartnered women (Table 6), a partner's erectile dysfunction led to twice as many negative repercussions on their own sexual desires as for other women $(42 \%$ vs $21 \%, P<0.01)$. It more profoundly affected the quality of their sexual lives in general ( $54 \%$ vs $23 \%$ of non-repartnered women, $P<0.001$ ).

Although discussion of problems surrounding sexual desire or erectile dysfunctions often seemed to be difficult for men to initiate, regardless of their relationship

Table 5. More distress due to erectile dysfunction for repartnered men.

\begin{tabular}{cccc}
\hline & $\begin{array}{c}\text { Repartnered male } \\
\text { response (\%) }\end{array}$ & $\begin{array}{c}\text { Non repartnered } \\
\text { male response (\%) }\end{array}$ & $P$ value \\
\hline Sexual QoL & 46 & 31 & $P<0.01$ \\
Self confidence & 42 & 24 & $P<0.001$ \\
Mood & 50 & 34 & $P<0.01$ \\
$\begin{array}{c}\text { Harmony in } \\
\text { relationship }\end{array}$ & 44 & 27 & $P<0.001$ \\
$\begin{array}{c}\text { Sexual desire } \\
\text { Feelings for partner }\end{array}$ & 49 & 30 & $P<0.01$ \\
$\begin{array}{c}\text { Psychological well } \\
\text { being }\end{array}$ & 46 & 20 & $P<0.05$ \\
\hline
\end{tabular}

(Answer "A Lot" and "Very Much" to question 30 "Would you say that these erectile problems had an impact on). 
Table 6. More distress due to erectile dysfunction for repartnered women.

\begin{tabular}{cccc}
\hline & $\begin{array}{c}\text { Repartnered couple } \\
\text { female } \\
\text { response (\%) }\end{array}$ & $\begin{array}{c}\text { Non repartnered } \\
\text { couple female } \\
\text { response (\%) }\end{array}$ & $P$ value \\
\hline Sexual QoL & 54 & 23 & $P<0.001$ \\
Self confidence & 24 & 17 & $P<0.05$ \\
Mood & 30 & 21 & $P<0.01$ \\
$\begin{array}{c}\text { Harmony in } \\
\text { relationship }\end{array}$ & 36 & 16 & $P<0.01$ \\
$\begin{array}{c}\text { Sexual desire } \\
\text { Feelings for } \\
\text { partner }\end{array}$ & 42 & 21 & $P<0.05$ \\
$\begin{array}{c}\text { Psychological } \\
\text { well being }\end{array}$ & 40 & 9 & $P<0.05$ \\
\hline
\end{tabular}

(Answer "A Lot" and "Very Much" to question 30 "Would you say that these erectile problems had an impact on).

status (37\% vs $31 \%$ for repartnered vs non-repartnered men respectively), these discussions seemed to be easier for women $(41 \%$ vs $27 \%$ for repartnered vs non-repartnered women, $P<0.01)$.

\subsubsection{Consulting a Physician for Sexual Dysfunction}

It is often difficult to talk about sexual problems with a doctor, for men and women. Both repartnered individuals (35\% of men vs $32 \%$ of women, NS) and non-repartnered individuals ( $22 \%$ of men vs $32 \%$ of women) reported difficulty. In the case of erectile dysfunction, $59 \%$ of men living in repartnered couples consulted their physicians, compared to $41 \%$ of the others. Comparable percentages of women consult their physicians: $43 \%$ vs $42 \%$ for repartnered vs non-repartnered women, respectively (NS). If these difficulties are present, women more readily confide in their gynecologists and ask them advice $(64 \%)$, with no difference between the groups of women.

\section{Discussion}

In our study, among the 748 subjects living in a stable relationship with a partner, 149 (or 19.9\%) were members of repartnered couples, which confirms that repartnering has become increasingly common in recent years as a result of a rise in divorce rates (Skew et al, 2009) [15] (Lampard et al, 2007) [16].

The data collected from subjects forming repartnered couples seem to indicate greater sexual vitality and more interest for sexuality compared to the responses obtained in our study for the entire population, and the recent large international references (14) and French surveys (Giuliano et al, 2002) [17] in the frequency of sexual intercourse and interest in sexuality (Nicolosi et al, 2006) [18].

In those large surveys, which took into account the sex and age of each subject, the frequency of sexual intercourse declined regularly with age (Araujo et al, 2004) [19] (Beutel et al, 2008) [20], a pattern also observed for our entire population, but not for repartnered men, who seem to maintain their frequency of sexual intercourse as they age. This observation had been reported in one of the rare studies on sexuality in older remarried couples; in this study, $57 \%$ of remarried men and $54 \%$ of remarried women over 55 claimed to have active sex lives (Montenegro, 2004) [21].

After the end of a first stable relationship, very few people refuse to envisage a new romantic relationship, and a larger number say they want to have a new relationship (Villeneuve et al, 1991) [22]. Expectations and the need for the success of the relationship, especially for sexuality, are greater than in a first relationship (Beltzer et al, 2006) [23]. This likely explains the importance of feelings and love in the couple's sexuality and the fact that more attention is paid to the partner's pleasure in repartnered couples, for both men and women.

A greater capacity for dialogue and communication in repartnered couples may be explained by difficulties in expressing feelings in the first relationship and by the desire for the new relationship to succeed.

In our study, the frequency of female sexual dysfunction was little affected by relationship status (repartnered or non-repartnered). Low sexual desire was by far the most frequent dysfunction for women of all ages, as in other studies (Laumann et al, 2005 [14]) (Nicolosi et al, 2006 [18]) (Rosen et al, 2009 [24]). Our findings for other sexual dysfunctions in women, whether in repartnered or non-repartnered couples, are also similar to the findings of other studies.

For men, the main sexual dysfunction for all ages was premature ejaculation, whose frequency was comparable to that reported by E.O. Laumann (Laumann et al, 2005) (14) and other studies (Montorsi, 2005) [25] (Brock et al, 2009) [26] (Buvat et al, 2009) [27], but which was slightly higher for repartnered men (32\% vs $23 \%)$. Starting a new life with a new partner and modifying sexual habits may predispose these individuals to other difficulties, with higher sexual performance anxiety, although it may prevent problems associated with sexual desire. Erectile dysfunctions did not differ between repartnered couples $(13.5 \%)$, the entire population of our study study (14.4\%) and Laumann's population (13.3\%) [14]. But repartnered men and women experience more distress due to erectile dysfunction.

In contrast, lack of sexual desire were less common for repartnered men $(18 \%)$ than the other men in our study (24\%), who were comparable to Laumann's group (25.6\%).

Despite the strengths of our study (the sexuality of repartnered individuals), the study has a limitation: data on how long the repartnered and non-repartnered rela- 
tionships had lasted are not available, and it is known that the frequency of sexual intercourse tends to diminish globally with the duration of the relationship (Laumann, 2005). Is the enhanced sexual vitality of our repartnered couples attributable to the new relationship, or to shorter duration of the relationship? We are currently conducting a prospective study to obtain this missing information.

\section{Conclusions}

The results of this study shed light on the sexual behavioral particularities and expectations of individuals in new heterosexual relationships, across a range of ages. These individuals seemed to benefit from greater sexual vitality but also encountered more dysfunctions, which were tolerated less well and were reinforced by higher anxiety and expectation rates than for the rest of the population. These data need to be completed and their validity confirmed by other studies providing information on the duration of the relationship at the time of the study.

It seems particularly important to take into account repartnered/non-repartnered status in future epidemiological studies on sexuality and its associated difficulties.

\section{REFERENCES}

[1] J. De Jong Gierveld, "Remarriage, Unmarried Cohabitation, Living Apart Together: Partner Relationships Following Bereavement or Divorce," Journal of Marriage and Family, Vol. 66, No. 4, 2004, pp. 236-243.

[2] G. Desplanques, "Les Familles Recomposées en 1990," Population et Sociétés, Vol. 286, 1994, pp. 1-4

[3] C. Barre and M. Vanderschelden, "Enquête Etude de l'Histoire Familiale de 1999," Résultats Détaillés, Insee Résultats Société, Vol. 33, 2004, pp. 1-4

[4] Statistique Canada, "La Diversification de la vie Conjugale au Canada,” Enquête Sociale Générale, 2002.

[5] E. B. Visher, J. S. Visher and K. Pasley, "Remarriage Families and Stepparenting," In: F. Walsh, Ed., Normal family Processes: Growing Diversity and Complexity, New York, 2003, pp. 153-175. doi:10.4324/9780203428436_chapter_6

[6] P. R. Ulin, E. T. Robinson, E. E. Tolley and T. T. Mc Neil, "Qualitative Methods: A Field Guide for Applied Research in Sexual and Reproductive Health," Family Health International, Vol. 6, No. 21, 2002, pp. 286-278.

[7] M. Hirsh, C. Donatucci, S. Glina, D. Montague, F. Montorsi and M. Wyllie, "Standards of Clinical Trials in Male Sexual Dysfunction: Erectile Dysfunction and Rapid Ejaculation," In: T. F. Lue, R. Basson, R. Rosen, F. Giuliano, S. Khoury and F. Montorsi, Eds., 2nd International Consultation on Sexual Dysfunctions, Health Publication Ltd, Plymouth, 2004, pp. 223-240.

[8] D. McGovern, W. Summerskill, R. McManus, M. Levi and R. Valori, "Evidence-Based Medicine in General
Practice," Bios Scientific Publishers Ltd, Oxford, 2003.

[9] ASCF Principal Investigators and Their Associates, "Analysis of Sexual Behavior in France (ACSF): A Comparison between Two Modes of InvestigationTelephone Survey and Face-Toface Survey," AIDS, Vol. 6, 1992, pp. 315-323.

[10] N. Bajos, M. Bozon, N. Beltzer and M. Godelier, "Enquête sur la Sexualité en France: Pratiques Genre et Santé," La découverte, Paris, 2008.

[11] M. H. Colson, A. Lemaire, P. Pinton, P. Klein and K. Hamidi, "Sexual Behaviors and Mental Perception, Satisfaction and Expectations of Sex Life in Men and Women in France," Journal of Sex Medicine, Vol. 3, 2006, pp. 121-132. doi:10.1111/j.1743-6109.2005.00166.x

[12] M. H. Colson and A. Lemaire, "Les Points Cardinaux de la Sexualité, Enquête sur la Sexualité des Français Aujourd'Hui," Médecine Sexuelle, Vol. 1, No. 1, 2007, pp. 22-26.

[13] A. Lemaire, M. H. Colson, B. Alexandre, B. Bosio-leGoux and P. Klein, "Why is That Patients with Sexual Difficulties Do Not Consult a Doctor More Frequently? The Results of a French Survey by the French Association for the Development of Information and Research in the Field of Sexology," Sexologies, Vol. 18, No. 1, 2009, pp. 14-18. doi:10.1016/j.sexol.2008.09.005

[14] E. O. Laumann, A. Nicolosi, D. B. Glasser, A. Paik, C. Gingell, E. Moreira and T. Wang, "Sexual Problems among Men and Women Aged 40-80y: Prevalence and Correlates Identified in the Global Survey of Sexual Attitudes and Behaviors," Journal of Impot Research, Vol. 17, 2005, pp. 39-57. doi:10.1038/sj.ijir.3901250

[15] A. Skew, A. Evans and E. Gray, "Repartnering in the United Kingdom and Australia," Journal of Comparative Family Studies, Vol. 40, 2009, pp. 561-1146.

[16] R. Lampard, “Couples' Places of Meeting in Late 20th Century Britain: Class, Continuity and Change," European Sociological Review, Vol. 23, No. 3, 2007, pp. 357 371. doi:10.1093/esr/jcm004

[17] F. Giuliano, M. Chevret-Measson, A. Tsatsaris, C. Reitz, M. Murino and P. Thonneau, "Prevalence of Erectile Dysfunction in France: Results of an Epidemiological Survey of a Representative Sample of 1004 Men," European Urology, Vol. 42, No. 3, 2002, pp. 382-389. doi:10.1016/S0302-2838(02)00323-8

[18] A. Nicolosi, E. O. Laumann, D. B. Glasser, G. Brock, R. King and C. Gingell, "Sexual Activity, Sexual Disorders and Associated Help-Seeking Behavior among Mature Adults in Five Anglophone Countries from the Global Survey of Sexual Attitudes and Behaviors," Journal of Sex Marital Theroy, Vol. 32, 2006, pp. 331-342. doi:10.1080/00926230600666469

[19] A. B. Araujo, B. A. Mohr and J. B. McKinlay, "Changes in Sexual Function in Middle-Aged and Older Men: Longitudinal Data from the Massachusetts Male Aging Study," Journal of the American Geriatrics Society, Vol. 52, 2004, pp. 1502-1509. doi:10.1111/j.0002-8614.2004.52413.x

[20] M. E. Beutel, Y. Stöbel-Richter, E. Brähler, "Sexual De- 
sire and Sexual Activity of Men and Women across Their Lifespans: Results from a Representative German Community Survey," British Journal of Urology International, Vol. 101, 2008, pp. 76-82.

[21] X. Montenegro, "The Divorce Experience: A Study of Divorce at Midlife and Beyond Research Report," AARP Knowledge Management, 2004.

[22] C. Villeneuve_Gokalp, "Du Premier au Deuxième Couple: Les Différences de Comportement Conjugal Entre Hommes et Femmes," In: T. Hibert and L. Roussel, La nuptialité: Evolution récente en France et dans les pays développés, Paris, 1991, pp. 179-192.

[23] N. Beltzer and M. Bozon, "Sexual Activity after Conjugal Separation, Women and the Age Constraint," Population-E, Vol. 61, No. 4, 2006, pp. 457-472.

[24] R. C. Rosen, J. L. Shifren, B. U. Monz, D. M. Odom, P. A. Russo and C. B. Johannes, "Correlates of Sexually Related Personal Distress in Women with Low Sexual Desire," Journal of Sex Medicine, Vol. 6, No. 6, 2009, pp.
1549-1560. doi:10.1111/j.1743-6109.2009.01252.x

[25] F. Montorsi, "Prevalence of Premature Ejaculation: A Global and Regional Perspective," Journal of Sex Medicine, Vol. 2, 2005, pp. 96-102. doi:10.1111/j.1743-6109.2005.20369.x

[26] G. B. Brock, F. Bénard, R. Casey, S. L. Elliott, J. B. Gajewski and J. C. Lee, "Canadian Male Sexual Health Council Survey to Assess Prevalence and Treatment of Premature ejaculation in Canada," Journal of Sex Medicine, Vol. 6, No. 8, 2009, pp. 2115-2123. doi:10.1111/j.1743-6109.2009.01362.x

[27] J. Buvat, D. Glasser, R. C. Neves, F. G. Duarte, C. Gingell and E. D. Jr. Moreira, "Global Study of Sexual Attitudes and Behaviours (GSSAB) Investigators' Group Sexual Problems and Associated Help-Seeking Behavior Patterns: Results of a Population-Based Survey in France," International Journal of Urology, Vol. 16, No. 7, 2009, pp. 632-638.

doi:10.1111/j.1442-2042.2009.02316.x 


\section{Appendix}

With exception of questions 1 and 33 (open questions), 2, 3, 14, 26, 30, 37 and 37 bis (multiple topics, one answer per topic) and 11, 22, 35, 36, 39, 40 and 41 (multiple choice), only one answer per question was allowed.

1) On hearing the word sexuality, which three words, adjectives or expressions come to mind? (love, feelings, intimacy, desire, sex, erotism, pleasure, liberty, couple, family, children),

2.1) Generally, is it easy for you to talk about sex with your:

- Partner? Very easy, Rather easy, Rather difficult, Very difficult

- Parents? Very easy, Rather easy, Rather difficult, Very difficult

- Children? Very easy, Rather easy, Rather difficult, Very difficult

- Friends/Colleagues? Very easy, Rather easy, Rather difficult, Very difficult

2.2) Do you feel that you think about sexuality frequently? Yes or No

3) In everyday life, do you find it easy to talk about:

- Contraception? Yes or No

- Your sexual practices? Yes or No

- The prevention of sexually transmitted diseases? Yes or No

- Problems such as the absence of desire or erection difficulties? Yes or No

- Feelings related to love? Yes or No

4) Have you ever talked about your sexuality or sexual problems with:

- A general practitioner? Often, Sometimes, Never

- A gynecologist? Often, Sometimes, Never

- A psychotherapist, Psychiatrist, or Psychoanalyst? Often, Sometimes, Never

- A urologist? Often, Sometimes, Never

- A sexologist? Often, Sometimes, Never

- Another specialist practitioner (cardiologist, etc.)? Often, Sometimes, Never

5) In your life today, is sexuality: Essential, Very important, Rather important, Rather unimportant, Not important at all

6) Would you find not making love for several months? Unbearable, Annoying, Frustrating, Indifferent, Not annoying at all

7) Conversely, would you in anyway feel relieved not to have to make love for several months? Yes definitely, Yes perhaps, No probably, No certainly not

8.1) Do you have a sexual partner? Yes or No

8.2) Do you ever feel desire for people other than your sexual partner? Very often, Often, Rarely, Never

8.3) Do you have the same sexual desire during periods of work-related stress? Yes or No

9) Do you believe that foreplay is: Essential, Very important, Quite important, Fairly unimportant, Not im- portant at all

10) If you believe foreplay is important, foreplay is important: More for you, More for your partner, For both of you

11) What are the two most important senses when you make love? Touch, Taste, Smell, Hearing, Vision

12) What is important in your sexual practices? Vaginal penetration, Enjoyment, Closeness with partner, Foreplay, Having simultaneous orgasms, All of the above, None of the above

13) What is the more important when you make love? Physical pleasure, Emotions and feelings, Relaxation and the well being that is felt afterwards, Both physical pleasure and emotional aspects

14) When you make love:

- Do you tend to try to give the most pleasure possible? Always, Often, Rarely, Never

- Do you tend to try to receive the most pleasure possible? Always, Often, Rarely, Never

- Do you tend to try to perform well? Always, Often, Rarely, Never

15) When do you prefer making love? In the morning, At lunchtime, At naptim , At bedtime, In the middle of the night, No particular time

16) When do you make love most often? In the morning, At lunchtime, At naptime, At bedtime, In the middle of the night, No particular time

17) In which season do you prefer making love? Spring, Summer, Fall, Winter, No particular season

18) Do you generally prefer to make love? In bed, Elsewhere

19) Do you generally prefer to make love? At home, In other places

20) When you make love, do you decide? A few seconds before, A few minutes before, A few hours before, $A$ few days before

21) On average, how many times per week do you have sex? Never, less than once a week, Between 1 and 2 times a week, Between 2 and 3 times a week, Between 3 and 4 times a week, More than 4 times a week

22) What prevents you from having sex most often? You don't have the desire, Your partner doesn't have the desire, You don't have enough time, Tiredness, Fear of failure, Lack of love, Lack of privacy, Taboos, prohibitions or upbringing, Other things to do, You are satisfied with the frequency, Lack of partner, single, Partner frequently absent, Age, Illness, Other causes

23) How would you rate your current sex life on a scale of 0 (fully unsatisfied) to 10 (fully satisfied)?

24) What would be your first wish with regard to your current sex life? To have sex more often, To have better quality sex, To have more sexual partners, For your partner to feel more desire, To have more time for sex, To be easily able to make love when you want to, Not to change anything

25) With regard to your current sex life, would you 
say that: You make love anytime you want to, there are no time restraints, You would like to be more able to choose the time

26) Do you agree with the following statements:

- "A lot of men have erectile dysfunction" Fully agree, Somewhat agree, Somewhat disagree, Fully disagree

- "These days, there are very effective medications available for erectile dysfunction" Fully agree, Somewhat agree, Somewhat disagree, Fully disagree

- "These days, men do not hesitate to consult a physician for erectile dysfunction" Fully agree, Somwhat agree, Somewhat disagree, Fully disagree

- "We are poorly informed about problems related to erectile dysfunction" Fully agree, Somewhat agree, Somewhat disagree, Fully disagree

27) Do you think that the decision to resort to this type of treatment (for erectile dysfunction) depends on: The couple, Only on the man

28.1) (Men) Have you ever had problems getting an erection? Yes or No

28.2) (Women) Has your partner ever had problems getting an erection? Yes or No

29.1) (Men) Have you ever had erectile problems that worried you? Yes or No

29.2) (Women) Has your partner ever had erectile problems that worried you or him? Yes or No

30) Would you say that these erectile problems had an impact on:

- The quality of your sexual life? A lot, Moderately, Not very much, Very much

- Your self-confidence? A lot, Moderately, Not very much, Very much

- Your mood? A lot, Moderately, Not very much, Very much

- Your feelings towards your sexual partner? A lot, Moderately, Not very much, Very much

- The feelings of your sexual partner towards you? A lot, Moderately, Not very much, Very much

- The harmony in your relationship? A lot, Moderately, Not very much, Very much

- Your general equilibrium? A lot, Moderately, Not very much, Very much

- Your sexual desire? A lot, Moderately, Not very much, Very much

- Your everyday relations with the outside world? A lot, Moderately, Not very much, Very much

31.1) (Men) Have you ever used a medical treatment (pill, injection, ...) for erectile dysfunction? Yes or No

31.2) (Women) Has your partner ever used a medical treatment (pill, injection, ...) for erectile dysfunction? Yes or No

31.3) Were you (if you are a man) or your partner (if you are a woman) satisfied with the treatment for erectile dysfunction? Yes absolutely, Yes somewhat, Not really, Not at all

32) Would you (if you are a man) or your partner (if you are a woman) use a treatment for erectile dysfunction if you/he had erection problems? Yes certainly, Yes perhaps, No probably not, No certainly not

33) Why were you not satisfied with or why would you not use a treatment for erectile dysfunction? You don't trust these products, You are afraid of adverse events, You do not want anything that is not "natural", You are afraid of becoming dependent, You are afraid that others will find out, These products are not fully effective, No interest, no need

34) When you think about your sex life in the future, what do you fear? Ceasing to be desirable, Problems related to sexual desire, Diminution in the frequency of sexual intercourse, Sexual difficulties, No longer getting on with your partner, Getting old, AIDS/Sexually transmitted diseases, Diminution of pleasure experienced, None of these reasons

35) To the men: Do you have:

- Erectile problems? Yes or No

- Early ejaculation? Yes or No

- Absence of ejaculation? Yes or No

- A diminution of sexual desire? Yes or No

- Other problems? Yes or No

35) To the women: Do you have:

- Impossible vaginal penetration? Yes or No

- Painful vaginal penetration? Yes or No

- A diminution of sexual desire? Yes or No

- Orgasm disorders? Yes or No

- Other problems? Yes or No

36.1) Do you inform yourself about sex? Yes or No

36.2) How? Daily press, General magazines, Specialist magazines, Television, Radio, Internet, Acquaintances (friends, family, colleagues), General practitioner, Gynecologist, Other specialist practitioner, Books, At work

36.3) If a specialist practitioner, which? Urologist, Psychiatrist/Psychologist, Sexologist, Other

37) What is the best stimulus for making love? Good wine, A good meal, A good movie, Having a good time together, Sports, An erotic movie, A prolonged absence of the sexual partner

38) In your opinion, compared with the national average, the women (if you are a man) or the men (if you are a woman) of your region are:

$\begin{array}{lr}\text { - More Less/As } & \text { Available. } \\ \text { - ore/Less/As } & \text { Affectionate. } \\ \text { - ore/Less/As } & \text { Faithful. } \\ \text { - ore/Less/As } & \text { Interested in sex. } \\ \text { - More/Less/As } & \text { Imaginative. } \\ \text { - More/Less/As } & \text { Good-looking } \\ \text {-More/Less/As } & \text { Attractive. } \\ \text {-More/Less/As } & \text { Easy-going. } \\ \text {-More/Less/As } & \text { Sensual. }\end{array}$

-Better/Worse/Just as good As sexual partners.

39) In your opinion, compared with the national average, people in your region make love: Somewhat more often/ Somewhat less often/As often. 